The volume is divided into three parts: "Basic Sciences", "Applied Sciences" and "Miscellaneous", the second of these is further sub-divided into agricultural, engineering and medical sciences. Within each division the organizations are listed alphabetically, those limited to a particular geographical area being placed at the end of the appropriate part or section under the heading "Regional". Details pertaining to the organizations are based on a questionnaire sent out to each, asking for information on the following sixteen points: official name, address, nature, aims, governing bodies and officers, membership, commissions, facilities, finances, meetings, voting, publications, relations with other international organizations, short history, bibliography and comments. With regard to 'nature', an organization may be inter-governmental, nongovernmental or semi-governmental; the first includes all those established through an inter-governmental agreement or diplomatic convention, and the last those which, though they include governments among their members, were not created by an intergovernmental agreement. An adequate subject index completes the work.

A final minor, but by no means unimportant, point may be mentioned. Why do some of these international bodies inflict us with the all-too-common habit of an uncouth collection of initial capital letters (sometimes making a pronounceable word, a practice which is even more uncouth) as an abbreviation of their full title? Most of us take in our stride FAO, WHO and UNO (though to the French-speaking world it is ONU) ; but how many can recognize, say, III, URSI or (shades of refrigeration) ICES ? The easiest way to decipher these is to glance rapidly down the six pages of contents of the Directory where the abbreviations are put in brackets after the full name of the entry. In all fairness, it must be stated that less than half the organizations are encumbered with one of these monstrous alphabetical arrays. As an aid to such identification alone, this Directory should prove very useful, and as a general work of reference it can be highly recommended.

\section{EARLY SCIENCE AT HARVARD}

Some Early Tools of American Science

An Account of the Early Scientific Instruments and Mineralogical and Biological Collections in Harvard University. By I. Bernard Cohen. Pp. xxi+201+ 32 plates. (Cambridge, Mass: Harvard University Press ; London: Oxford University Press, 1950.) 38s, net.

$\mathrm{A}$ $\mathrm{N}$ increasing awareness of the far-reaching effects of science on human civilization has led to a desire to know something of the origins of science. During the past few years the British Society for the History of Science has been formed, and the Department of the History and Philosophy of Science in the University of London has increased its activities. At Oxford and Cambridge the University authorities are taking added interest in their Museums for the History of Science. Nevertheless, at the sixth International Congress for the History of Science, held at Amsterdam last August, it was frequently stressed that there is a dearth of teachers of the subject.

The activity in Great Britain is matched by similar developments in the United States, and Dr. Bernard
Cohen, professor of general education and of the history of science in Harvard University, is one of the leading investigators in the United States. This present book, one of several to his credit, has been written around the catalogue of the early scientific instruments placed on exhibition at Harvard in February 1949. Searching through the manuscripts and contemporary records in the college archives to find something about these instruments, Prof. Cohen extracted and recorded in his book all information bearing on the early scientific work at Harvard, so that it is possible to form a tolerably clear picture of the state of science there in the eighteenth and early nineteenth centuries. The difficulties under which the Hollis professors at Harvard worked are clearly discernible. Their instruments and apparatus had to be purchased and, if necessary, repaired in England ; and the Atlantic crossing, in those days under sail, took at least two months for the double journey. Much of the purchasing was done by helpful agents or friends, and, as communication was slow, it had to be left to them to select what apparatus they thought might be of use and to consign it to Harvard. The products were thus obtained of the major British instrument makers: Edward Nairne, J. Gilbert, Benjamin Martin, George Adams and W. and S. Jones.

Prof. Cohen is a partisan whose concern it is to establish the pre-eminence of Harvard science and to refute Barrett Wendell's statement that the University had not during the eighteenth century attempted to acquire and publish fresh knowledge; but when part of the evidence for original work cited by Dr. Cohen is a paper by Prof. Samuel Williams on "a very uncommon Darkness in the States of New-England, May 19, 1780", conviction is scarcely carried.

Reading between the lines, we get the impression that the apparatus was not extensively used. The lecture syllabuses which Prof. Cohen quotes at length refer mainly to astronomy and mathematics. These were old-established subjects, which had been taught and studied since classical times and should be distinguished from the newer natural, or experimental, philosophy which was being developed in Europe at the time and was the true forerunner of present-day science. It seems clear that those who received their apparatus unselected, by the crateful, would not have the same enthusiasm for it as those in Europe who were actually devising it and instructing the makers as to its design; and it is possible that much of it remained untouched in the cupboards for long periods.

If we do not agree with the author in his estimate of the worth of the early science at Harvard, we are nevertheless grateful to him for having so carefully collected all the evidence and having presented it in a readable and well-documented form. Besides the chapters dealing with the instruments, there is a chapter on the chemistry teaching, and another on biology and mineralogy. The catalogues and lists of scientific apparatus which form the appendixes of the book (forty-four pages of text and twenty-four pages of illustrations) are extremely useful for those interested in early scientific instruments. It is a pleasing feature that there are photographs of all the forty-six objects described in the catalogue of the 1949 exhibition, and it was a happy idea to illustrate an inventory of apparatus made in 1738 by reproductions of the plates from a book of the period.

H. R. Calvert 